\title{
The indirect aerosol effect over Europe
}

\author{
Olaf Krüger \\ Meteorologisches Institut, Universität Hamburg, Germany
}

Hartmut Graß1

Meteorologisches Institut, Universität Hamburg and Max-Planck-Institut für Meteorologie, Germany

Received 17 September 2001; revised 28 March 2002; accepted 5 April 2002; published 10 October 2002.

[1] In order to assess the influence of anthropogenic emissions on cloud albedo over Europe a reprocessed set of satellite measurements from 1985 to 1999 was investigated. Special emphasis was given to the Central European main emission area, including the so-called 'Black Triangle' which covered parts of Germany, the Czech Republic and Poland. Due to the decrease of aerosol precursor gases the analysis reveals a pronounced decrease of cloud albedo of about $2 \%$ from the late $80 \mathrm{~s}$ to the late $90 \mathrm{~s}$. During winter in source regions of anthropogenic particulate matter emissions the cloud reflectance is more than 5\% lower referring in addition to an absorption effect caused by black carbon in clouds. The comparison with emission data as well as model results of long range transport over Europe strongly supports the conclusion that the changed indirect aerosol effect is responsible for significantly changed cloud optical properties. Radiative transfer calculations indicate for the classical Twomey effect a change in radiative forcing of about $1.5 \mathrm{~W} / \mathrm{m}^{2}$ from the late $80 \mathrm{~s}$ to the late $90 \mathrm{~s}$. In addition during winter a radiative forcing of about $3 \mathrm{~W} / \mathrm{m}^{2}$ due to the absorption effect for both the late $80 \mathrm{~s}$ and the late $90 \mathrm{~s}$ is estimated. INDEX TERMS: 3359 Meteorology and Atmospheric Dynamics: Radiative processes; 3339 Meteorology and Atmospheric Dynamics: Ocean/atmosphere interactions (0312, 4504); 3374 Meteorology and Atmospheric Dynamics: Tropical meteorology; 3319 Meteorology and Atmospheric Dynamics: General circulation; 1821 Hydrology: Floods. Citation: Krüger, O., and H. Graß1, The indirect aerosol effect over Europe, Geophys. Res. Lett., 29(19), 1925, doi:10.1029/2001GL014081, 2002.

\section{Introduction}

[2] Radiative forcing of climate due to the influence of tropospheric aerosols on cloud albedo is highly uncertain. One reason is that this indirect aerosol effect is always a combination of two competing processes. Firstly, aerosols act in part as cloud condensation nuclei. For constant cloud liquid water content an increasing number of condensation nuclei would shift the mean droplet size to smaller radii. In theoretical studies [Twomey, 1974] it has been shown, that this process may increase cloud albedo strongly, especially for thin stratus decks. Besides this influence of aerosols on droplet number and size there is a second process acting on cloud albedo: absorption by aerosol particles (e.g. black carbon or soot, fly ash). The interaction of both processes determines the radiative characteristics of clouds and consequently the cloud albedo [Graßl, 1975; Twomey, 1977].

Copyright 2002 by the American Geophysical Union. 0094-8276/02/2001GL014081
[3] Mainly based on model results, the Intergovernmental Panel on Climate Change (IPCC) estimated the indirect aerosol forcing to be negative, reaching in the global mean up to $2 \mathrm{~W} / \mathrm{m}^{2}$ [Climate Change, 2001]. But this estimate is marked as highly uncertain and even a negligible indirect effect seems possible. The objective of the present study was to determine cloud albedo changes with time as a function of emission characteristics for Central Europe, where major emission changes have occurred especially after the fall of the Berlin wall. We used official emission inventories and operational satellite data, i.e. the Pathfinder data set published by NASA containing measurements from AVHRR sensors on several NOAA satellites. In order to exclude the potential effect of volcanoes only satellite measurements within the periods 1985-1989 and 1996-1999 were investigated, largely free of volcanic aerosols in the stratosphere.

\section{Observation of Cloud Reflectances}

[4] Since the crucial point of the study is the evaluation of long term cloud reflectances over Europe the reprocessed global NOAA/NASA Pathfinder data set from the Advanced Very High Resolution Radiometers (AVHRR) on board the afternoon-viewing NOAA series satellites (NOAA-7, 9, 11, and 14) was used. The data set has been processed by NASA using best available methods for a consistent time series of unprecedented quality. Methods used in preprocessing include cross-satellite calibration, application of a precision navigation system and correction for Rayleigh scattering [James and Kalluri, 1994]. The AVHRR instrument measures both reflected solar and emitted terrestrial radiation in five spectral channels which take advantage of maximum transmittance in the atmospheric windows. The instrument enables a detailed cloud detection. In this study, for delineating optical characteristics of clouds, the NOAA/NESDIS algorithm [Stowe et al., 1991] was applied. The technique utilizes the five-channel AVHRR multi-spectral information, individual values as well as spatial differences, in series of sequential decision-tree type tests and includes established or empirically optimized thresholds. The procedure allows to identify cloud-free, mixed and cloudy atmospheres. The cloud detection is based on the magnitudes of emitted and reflected radiation, the wavelength dependence and spatial variability.

\section{Evaluation of Satellite Measurements}

[5] The indirect aerosol effect is difficult to assess from an instantaneous satellite image. It appears to be nearly impossible to interpret a cloud system in individual satellite 


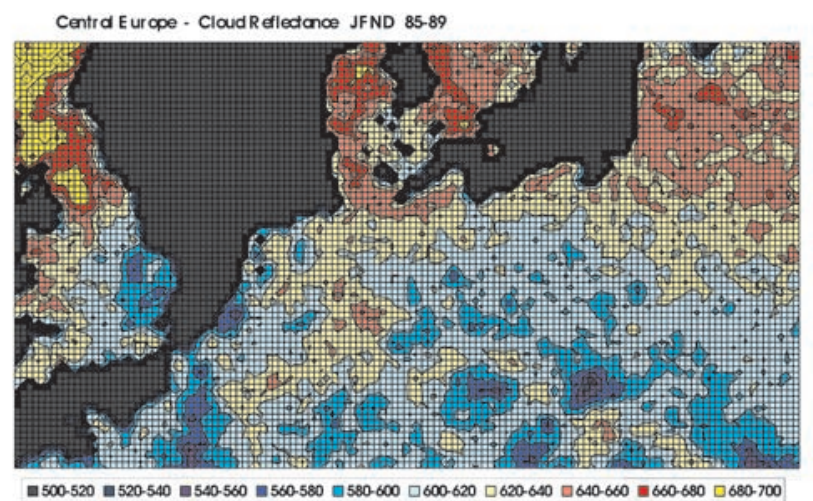

Figure 1. Mean cloud reflectance derived from AVHRR channel 2 satellite measurements over parts of Central Europe in thousandth. Data are shown from $-5.0^{\circ}$ to $28.5^{\circ}$ longitude and $48.5^{\circ}$ to $57.5^{\circ} \mathrm{N}$ for the winter period (January, February, November, December) from 1985 to 1989 (excluding data from 1987).The grid size is $0.25^{\circ}$ longitude and $0.125^{\circ}$ latitude. The area covers parts of UK, Denmark, Sweden, France, Benelux, Germany, Poland, Czech Republic and Ukraine. The North Sea and the Baltic Sea are in black.

pictures without information on cloud development. Also cloud water content should be known to derive the order of magnitude of the indirect effect. Further, because of the complex characteristics of the formation of secondary aerosols and the various processes being involved in cloud microphysics it is a comprehensive task to follow anthropogenic emissions from the source to the receptor cloud system. It is also easier to catch the indirect effect at or near the source regions of anthropogenic emissions. The interpretation of the indirect effect in more remote regions would demand mesoscale and regional modeling including radiative transfer. However, since indications for the indirect effect known from measurements are rare, we assume that modeling may not describe the cloud aerosol interactions adequately at present.

[6] In order to detect the indirect effect we decided to analyze long term changes of cloud reflectance in satellite measurements. Therefore we evaluated the AVHRR channel 2 frequency distributions of cloud reflectance for all cloudy pixels. Special emphasis was given to the mesoscale spatial variability over Central Europe. Channel 2 was chosen because of minor influence of Rayleigh scattering. As the aim also was to strongly reduce inter-annual variability, we considered frequency distributions over 4 years. We focused our evaluation on two main aspects:

The comparison of cloud reflectance for two episodes of distinct amount of $\mathrm{SO}_{2}$ emission.

The analysis of spatial heterogeneity of cloud reflectance.

[7] Applying an algorithm for cirrus cloud detection the intension was to restrict the evaluation to water clouds. The parameters of interest were the arithmetic mean, the coefficient of variation, the standard deviation and the frequency of occurrence of water clouds. Since we expected the indirect aerosol effect mostly near the strong emission sources of PPM and $\mathrm{SO}_{2}$ the area of interest was Central Europe including parts of Western and Eastern Europe (longitude $-5^{\circ} \mathrm{W}$ to $31^{\circ} \mathrm{E}$, latitude $48^{\circ} \mathrm{N}$ to $60^{\circ} \mathrm{N}$ ). The former GDR is in the centre of this area, a region of extremely high emissions of precursor gases as well as primary particles during the period 1985 to 1989 with stronger contributions from elevated point sources as compared to other European countries.

[8] We investigated the influence of air pollution on the reflectance of clouds for the four-year periods from 1985 to 1989 (excluding 1987 because of problems with data for several months) and from 1996 to 1999 . In our study we considered also seasonal differences. The winter episode covers the months January, February, November and December of four years (hereafter referred to as JFND8589 and JFND9699 respectively), the summer episode includes data from May, June, July and August of four years (MJJA8589, MJJA9699).

[9] The EMEP model results [EMEP, 2000] show that in our area of interest there exist strong gradients of annual mean concentrations of PM from more remote regions to the emission areas which we name source regions. The location of extreme values of the mean AVHRR reflectance is found in areas of above $20 \mu \mathrm{g} / \mathrm{m}^{3} \mathrm{PM}$. These source regions contain significantly increased PM concentrations as compared to remote regions with $5 \mu \mathrm{g} / \mathrm{m}^{3}$.

[10] The annual mean $\mathrm{SO}_{2}$ concentrations vary from 1 $\mu \mathrm{g} / \mathrm{m}^{3}$ (sulphur) in remote regions to above $10 \mu \mathrm{g} / \mathrm{m}^{3}$ over the former GDR, the Czech Republic and Poland. The areas of lowest mean reflectance during winter (see Figure 1) and the areas of highest mean reflectance during summer (see Figure 3) are nearly identical with the areas of highest PM concentrations, or highest $\mathrm{SO}_{2}$ concentrations respectively. While we see several minima of reflectance over Central Europe the pattern is more homogeneous during summer with a dominant maximum located over the Czech Republic and Poland.

\subsection{Indirect Aerosol Effects}

[11] In detail the spatial heterogeneity of the wintertime cloud reflectance over Europe shows a clear gradient from Great Britain, Scandinavia and former Soviet Union to the densely populated industrial regions of Central Europe with up to $10 \%$ smaller reflectance over Central Europe.

[12] Main emission centers show lower cloud reflectance in all western, central and eastern European countries evaluated so far for both the JFND8589 (Figure 1) and the JFND9699 period. The areas of minimum cloud reflectance with values even lower than $58 \%$ are located around London, Paris, Rotterdam, Frankfurt/Main, Leipzig, Prague, Kattowice, Cracow and Vienna. We interpret the strong reflectance decrease from remote to source regions by the impact of $\mathrm{BC}$ emissions originating mainly from power plants, small combustion and mobile sources. During JFND8589 also fly ash emitted from power plants should be taken into consideration.

[13] The long term difference of cloud reflectance for the total area is lower by about 2.8 percent in the period JFND9699 than during JFND8589 (Table 1). This is a further clear indication that the Twomey effect worked. However, our results also show that the magnitude of the Twomey effect is not only due to the increase of droplet concentration and thereby optical thickness, but also due to changes of the absorption coefficient, that becomes domi- 
Table 1. Mean Cloud Reflectances (in \%) Derived From AVHRR Channel 2 Satellite Measurements Over Parts of Central Europe $\left(-5.0^{\circ}\right.$ to $28.5^{\circ}$ Longitude and $48.5^{\circ}$ to $\left.57.5^{\circ} \mathrm{N}\right)$ for the Winter Period JFND (January, February, November, December) and for the Summer Period MJJA (May, June, July, August) From 1985 to 1989 (Excluding Data From 1987) and 1996 to 1999 Respectively

\begin{tabular}{lccc}
\hline & $1985-1989$ & $1996-1999$ & Difference \\
\hline Winter JFND & 61.5 & 58.7 & -2.8 \\
Summer MJJA & 65.7 & 63.6 & -2.1 \\
\hline
\end{tabular}

nant for optically thick clouds. The lower boundary layer height and the slow formation of secondary aerosols from precursor gases during winter favours the dominance of the absorption effect in source regions of Central Europe.

[14] The summertime cloud reflectance over Europe during MJJA8589 delivers a clear indication for the classical Twomey effect accompanied with higher reflectances which are initiated by increased droplet concentration (Figure 2). Eastern and Central Europe show higher cloud reflectivity in comparison to the British Isles and Western Europe. Individual metropolitan and industrial regions are no longer directly visible in cloud reflectance, pointing to decreased carbon emissions during summer and to a more rapid transformation of precursor gases into aerosol particles from gaseous emissions. The gradient of cloud reflectance from remote to polluted regions changes sign if compared to winter. Highest reflectances occur in regions of well known maximum sulphur dioxide concentrations over the black triangle of Europe. The average cloud reflectance decreases between MJJA8589 and MJJA9699 by about 2.1 percent (Table 1).

\subsection{Indirect Radiative Forcing of Tropospheric Aerosols}

[15] The long term differences of the measured reflectances if expressed solely by the classical Twomey effect are eqivalent to a decrease from $6 \mu \mathrm{m}$ to $3 \mu \mathrm{m}$ for the effective radius of the cloud droplets. Calculations with a numerical radiative transfer model [Key and Schweiger, 1998] for a stratus cloud over vegetation (cloud base $\sim 500 \mathrm{~m}$, cloud top $\sim 1000 \mathrm{~m}$, cloud liquid water content $0.2 \mathrm{~g} / \mathrm{m}^{3}$, single scattering albedo 0.997 and optical thickness 30) in a mid-latitude atmosphere including an urban aerosol model (optical thickness 0.66) translate this shift into a cloud forcing of about $1.5 \mathrm{~W} / \mathrm{m}^{2}$.

[16] As seen from the spatial heterogeneity of cloud reflectance in addition an absorption effect caused by $\mathrm{BC}$ emissions has to be considered. This is clearly indicated by the decrease of the measured reflectances from remote to source regions for both winter periods. Figure 1 shows strong gradients that occur from Scandinavia to Germany, from the western to the polluted eastern part of England and from Lithuania to Poland. But there is an even stronger gradient from East Europe to Central Europe (not shown in Figure 1).

[17] In radiative transfer calculations we neglect a radius effect of $\mathrm{BC}$ at the time of the emission since $\mathrm{BC}$ particles are hydrophobic and chemically inert [Crutzen et al., 1984]. We rather assume that the high amount of particles in source regions favour the physical transformation of black carbon into a hydrophilic form. Therefore the condensation close to source regions is based on internally mixed aerosol and consequently the albedo of cloud droplets is significantly reduced referring to a single scattering albedo of about 0.997. Due to wet deposition the black carbon content in aerosols decreases in remote areas with distance from sources. An additional explanation for the absorption effect might be that low clouds in source regions contain a higher portion of $\mathrm{BC}$ particles in the interstitial aerosol. For quantifying the absorption effect we take into account a $5 \%$ smaller reflectance over the densely populated industrial regions of Central Europe which is equivalent to a reduction of single scattering albedo from 0.999 to 0.997 for the stratus cloud above. The positive radiative forcing of this additional absorption is about $3 \mathrm{~W} / \mathrm{m}^{2}$ whose magnitude is higher than the $1.5 \mathrm{~W} / \mathrm{m}^{2}$ that originate from the Twomey effect for a $50 \%$ reduction of $\mathrm{SO}_{2}$ emission.

[18] Combining the results for the radius effect and the absorption effect even a net positive radiative forcing for Central Europe might have been the case during the winters 85-89. Due to the strong decrease of $\mathrm{SO}_{2}$ emissions from 1989 to date the net forcing might even have increased during the 1990s. The rapid increase of private traffic in Central Europe and the growing share of diesel engines are given here as arguments. However, no BC emission trends have been published for this part of Europe. Therefore, it is too early to fix the sign of the indirect aerosol radiative forcing for strongly polluted regions.

\section{Discussion and Conclusions}

[19] The geographical location of the changes in cloud reflectance for the winter episodes caused by the absorption effect as discussed above is generally in accordance with modelled particulate matter [EMEP, 2000] using the best available information on emission inventories. Also black carbon emission inventories and model simulations Cooke and Wilson [1996] and Liousse et al. [1996] are in agreement with our results. The strongest decrease in cloud reflectance is seen exclusively around emission areas. According Twomey [1977] the decrease in reflectance as shown in Figure 1 would be roughly translated in a reduction of cloud optical thickness by $30-50 \%$ for optical

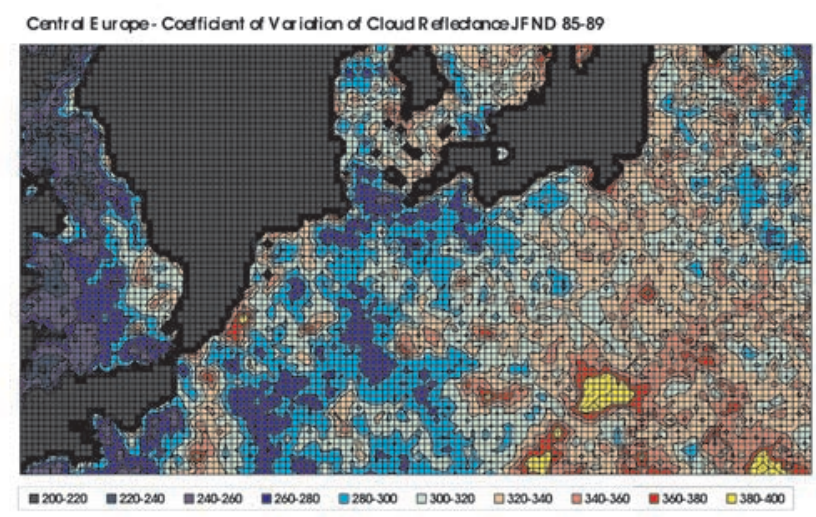

Figure 2. Mean coefficient of variation of cloud reflectance derived from AVHRR channel 2 satellite measurements over parts of Central Europe in hundredth. The area and the years are the same as for Figure 1. The numbers are due to the winter periods (January, February, November, December) from 1985 to 1989. 


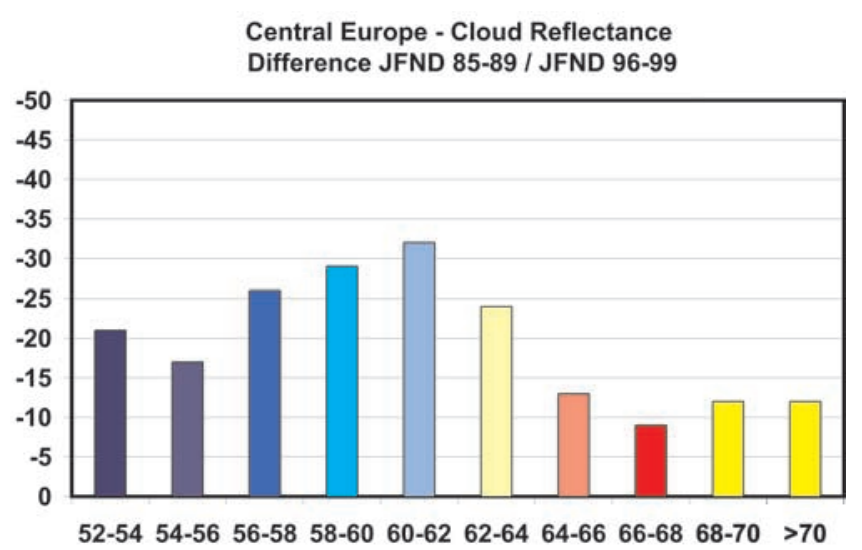

Central Europe - Cloud Reflectance Difference MJJA 85-89 / MJJA 96-99

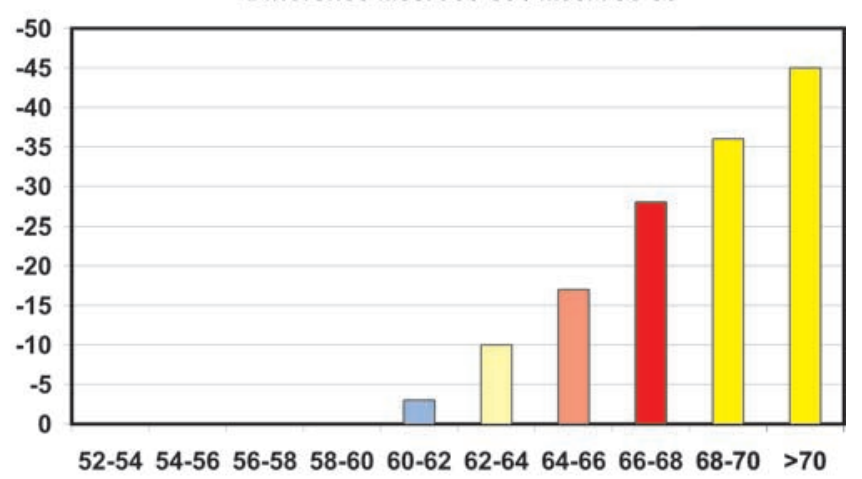

Figure 3. (a, b) Decrease of cloud reflectance in thousandth (axis of ordinate) from 85-89 to 96-99 for the different areas of mean reflectance (unit: \%) as depicted in Figures 1 and 2 (same colors).

thick clouds (optical thickness 50) and more than $50 \%$ for optical thin clouds (optical thickness 10). This makes it clear that such mesoscale reflectance patterns over Europe can not be explained by the natural variation of the cloud optical thickness. Except for an anthropogenic influence there is no other reason why clouds should have such a decreased optical thickness just over the areas of highest PM concentration.

[20] Regarding the radius effect we again exclude that the differences in reflectance are mainly caused by natural variability of the cloud optical thickness. Firstly during winter we see for the comparison of the two winter episodes the strongest reductions from $85-89$ to $96-99$ of about 3\% reflectance near the main emission centres (see Figure 3a). In remote regions we only have a decrease of $1 \%$ reflectance. It is not likely that based on climatological variations of the cloud optical thickness the reflectance in the vicinity of the emission sources of PPM and precursor gases has reduced by $3 \%$ while in remote regions the changes only amount to $1 \%$.
[21] During summer again we see the most pronounced radius effect over the regions of strongest pollution (Figure $3 b)$.

[22] These are the areas of highest $\mathrm{SO}_{2}$ concentrations during the 80 s were highest decrease in reflectance by more than $4 \%$ occurred. The remote regions show, as for winter, a decrease of only $1 \%$ reflectance. Again it is not likely that without an anthropogenic influence just in these regions over Poland and the Czech Republic the optical thickness of clouds has changed while the changes in remote areas are, as in winter, very small.

[23] We conclude that our study reveals evidence for the regional occurrence of an indirect aerosol effect over Europe. A pronounced seasonal variability of the indirect aerosol forcing is shown. The reduction of the sulphur dioxide emissions by about $50 \%\left(23 \mathrm{Tg} \mathrm{y}^{-1}\right)$ is accompanied by a change in radiative forcing of about $1.5 \mathrm{~W} / \mathrm{m}^{2}$. Further, black carbon emissions in the order of magnitude of $1 \mathrm{Tg} \mathrm{y}^{-1}$ reduce the cloud reflectance in source regions by more than 5\%. However, since information about BC emission changes is lacking a precise relation between $\mathrm{BC}$ emission and cloud albedo can not be given.

\section{References}

Climate Change, The scientific basis, contribution of Working Group I to the third assessment report of the Intergovernmental Panel on Climate Change, Intergovernmental Panel on Climate Change, Working Group I,

J. T. Houghton et al. (Eds.), Cambridge University Press, p. 881, 2001.

Cooke, W. F., and J. J. N. Wilson, A global black carbon aerosol model, Journal of Geophysical Research, 101(D14), 19,395-19,409, 1996.

Crutzen, P., I. Galbally, and C. Bruhl, Atmospheric effects from post nuclear fires, Climate Change, 6, 323-364, 1984.

EMEP, Status Report with respect to Measurements, Modelling and Emissions of Particulate Matter in EMEP: An integrated approach, Joint CCC and MSC-W Report 2000, EMEP MSC-W Note 5/00, August 2000 Meteorological Synthesizing Centre - West, Norwegian Meteorological Institute, P.O. Box 43 - Blindern, N-0313 Oslo, Norway, 2000.

Graß1, H., Albedo reduction and radiative heating of clouds by absorbing aerosol particles, Contributions Atmospheric Physics, 48, 199-210, 1975.

James, M. E., and S. N. V. Kalluri, The Pathfinder AVHRR land data set: An improved coarse resolution data set for terrestrial monitoring, International Journal of Remote Sensing, 15(17), 3347-3363, 1994.

Key, J. R., and A. J. Schweiger, Tools for Atmospheric Radiative Transfer: STREAMER and FLUXNET, Computers and Geosciences, Vol. 24, No.5, pp. 443-451, 1998

Liousse, C., J. E. Penner, C. Chuang, J. J. Walton, H. Eddleman, and H. Cachier, A global three-dimensional model study of carbonaceous aerosols, Journal of Geophysical Research, 101(D14), 19,411-19,432, 1996. Stowe, L. L., E. P. McLain, R. Carey, P. Pellegrino, G. G. Gutman, P. Davis, C. Long, and S. Hart, Global distribution of cloud cover derived from NOAA/AVHRR operational satellite data, Advances in Space Research, 11(3), (3) $51-(3) 54,1991$.

Twomey, S., Pollution and the planetary albedo, Atmospheric Environment, 8, 1251-1256, 1974.

Twomey, S., The Influence of Pollution on the Shortwave Albedo of Clouds, Journal of the Atmospheric Sciences, 34, 1149-1152, 1977.

O. Krüger, Meteorologisches Institut, Universität Hamburg, Bundesstraße 55, D-20146 Hamburg, Germany. (olaf.krueger@dkrz.de)

H. Graß1, Max-Planck-Institut für Meteorologie, Bundesstraße 55, D20146 Hamburg, Germany. (grassl@dkrz.de) 